\title{
Finding a Place for Agriculture in Intellectual Property Law
}

\author{
Susannah Chapman • Brad Sherman
}

Published online: 14 August 2018

(C) Max Planck Institute for Innovation and Competition, Munich 2018

Agricultural and intellectual property have a complex, but largely neglected history. Intellectual property has long played an important role in many areas of agriculture from the breeding of new crops and the design of farm equipment through to the way agricultural produce is described, marketed and labelled. Despite this, intellectual property law's interaction with agriculture has attracted comparatively little attention or interest. Over the last decade, the situation has changed, primarily as a result of a growing awareness of the role that intellectual property law plays in relation to food security. Given the use of new scientific and technical innovations across the food chain - whether the use of molecular markers in breeding, the adoption of nano-based biomarkers to trace proprietary products, or the increased use of precision agriculture and data-driven smart farming - it seems that this trend is only set to continue in the future.

Despite its importance, there has been comparatively little written about intellectual property law and its intersection with agriculture. To the extent that the topic has been addressed, it has been characterised by a concern with a limited number of areas of law, notably plants and plant genetic resources, late twentieth century international intellectual property agreements, and geographical indications of origin. The literature is also marked by a shared concern with legal doctrine (at the national and international level) and with reform-orientated policy arguments. While this work is important, to give justice to this important topic, it is necessary to broaden the way that we think about intellectual property law and agriculture.

\footnotetext{
S. Chapman

Research Fellow, TC Beirne School of Law, University of Queensland, Brisbane, Australia e-mail: susannah.chapman@uq.edu.au

B. Sherman $(\bowtie)$

Professor, ARC Laureate Fellow, TC Beirne School of Law, University of Queensland, Brisbane, Australia

e-mail: b.sherman@law.uq.edu.au
} 
To do this, the scope of intellectual property law should be expanded in two ways. The first is in terms of the attention we give to non-legal mechanisms that regulate and control the creation, circulation, and use of intangibles. Specifically, it relates to the question of whether non-state-based modes of regulation, as distinct from state-initiated legal mechanisms, should be included within the general intellectual property law rubric. What are we to make, for example, of a farmer who purposely infects livestock that he is selling with liver fluke in order to render them infertile: a practice designed to allow the farmer to control the reproduction of the biological capital that he had bred into the sheep? What of Stark Brothers' decision to build a cage around the original Golden Delicious tree to prevent third parties from appropriating the valuable genetic material embodied therein? While it is important not to equate intellectual property law with the regulation and control of intangibles generally, as some have done, (not because this offends some natural legal order, so much as that it potentially leads us to overlook what is interesting and distinct about the different modes of regulation), it is important to look at non-legal mechanisms of control (such as hybrid breeding and terminator technology), not least because these non-legal modes of regulation have the potential to impact on the scope and operation of the law.

The second way in which the scope of intellectual property law should be expanded is in terms of the areas of law we include within its remit. While it is important to include those areas of conventional intellectual property law that are of relevance (namely, patents, copyright, trade marks, and designs, plant patents, plant breeders' rights, and geographical indications of origin), it is also important to include a range of laws that are not traditionally thought of as forming part of intellectual property law, including seed certification laws, one-variety community laws, crop registration systems, pure food laws, along with schemes dealing with plant introductions and seed distribution. The justification for expanding the scope of intellectual property law in this way is twofold.

The first reason for extending the scope of intellectual property law so as to encompass these "unconventional" laws is because many of these pre-modern laws acted as precursors to the formation of the conventional law. In the same way in which, for example, pre-modern regimes in the United Kingdom, such as the 1711 Literary Property Act, the 1734 Engravings Copyright Act and the 1862 Fine Arts Copyright Act underpinned the formation of a modern abstract copyright law at the end of the nineteenth century, so too these early laws played an important role in the eventual assimilation of biological subject matter into mainstream intellectual property law. These unconventional laws also played a largely unexplored but important role in preconditioning agriculture and food production so that they were able to be accommodated within the traditional categories of intellectual property law. The fact that many seed certification laws today draw their technicalities and definitions from plant breeders' rights law is further testament to both the common historical roots and shared aims of "conventional" and "unconventional" intellectual property law. Indeed, in many parts of the world today, the creation of a system of seed certification is seen as a prerequisite for the creation of plant variety protection and patent law. 
The second reason for expanding the scope of intellectual property law to encompass unconventional areas of law such as the one-variety community laws or seed certification laws is because of the particular nature of biological subject matter and how it differs from machine-based subject matter. Although there are differences, one thing that the traditional categories of intellectual property law share in common is that they are all concerned, in one way or another, with regulating the creation, circulation, and use of intangibles. In most cases, this is achieved by separating out the intangible and tangible form of the subject matter. In the case of patents, for example, the ability to separate the intangible aspect of an invention from its material form allows the invention to be reduced to a written form in the specification. Importantly, third parties are able to repeat the invention from this written format. As the history of intellectual property law in plants, animals, and microorganisms makes clear, this was not possible with biological innovations.

In contrast to mechanical creations, which are able to be reproduced from the information represented in a patent disclosure, third parties are only ever able to reproduce biological creations when they have access to a viable instantiation of the physical form of the biological invention, such as the seed, germplasm or cutting. One of the consequences of this is that when dealing with biological innovations, the law has consistently relied upon the physical embodiment of the biological subject matter, whether to represent the intangible contribution inscribed in the thing itself, to ensure that third parties are able to repeat the invention, or to provide some certainty about the nature and identity of the thing that is protected. This has been achieved through a number of mechanisms including the deposit system (now reflected in the Budapest Treaty) or via the type-specimens that are inextricably linked to plant breeders' rights, plant patents, and utility patents for biological creations.

Recognizing the central place that the physical form plays in intellectual property law's interaction with biological subject matter has important consequences for the way that we think about intellectual property law. This is particularly the case when we also acknowledge that the physical form of the biological subject matter - the seed, germplasm, or cutting - may have an inherent capacity for reproduction. From this perspective, it could be argued that any regime that regulates the creation, circulation, or reproduction of tangible biological material (that has the capacity for self-replication) could be considered to be a type of intellectual property law. This is because a law that controls the creation, circulation or reproduction of tangible viable biological objects also necessarily controls the creation, circulation and reproduction of the intangible subject matter.

Historically, states and government agencies have devised an array of legal mechanisms to control the development and circulation of physical reproductive material. For example, one variety laws mandated the seed that could be planted, colonial seed storage laws dictated the terms of farmer seed saving and seed exchange, and seed certification laws - one of the few of "unconventional" interventions that persist today - regulated the circulation of planting materials. Like the emergence and expansion of conventional biological intellectual property, many of these "unconventional" laws were shaped by the transformation of breeding practices during the twentieth century, the collection of agricultural 
statistics, and the rise of statist, nationalistic agricultural policies geared toward managing concerns over food security and competitive advantages in global commodity markets.

Seeing intellectual property law in this way has a number of consequences. As well as opening up new, exciting, and largely unchartered areas of research, it will also improve our understanding of the ways in which intellectual property law interacts with agriculture, which has important ramifications for policy debate and reform. And for many developing countries, this extended reading of intellectual property law also offers an alternative sui generis means of implementing Art. 27(3)(b) of TRIPs (which requires Member States to protect plant varieties either by patents, by an effective sui generis system, or by any combination thereof). 